\title{
Perceived Stress and Resilience among Nurses Working in a Selected Hospital at Mangalore
}

\author{
Sujatha R. Kannappan ${ }^{1}$ Jacintha Veigas ${ }^{2}$ \\ 1 Department of Child Health Nursing, Nitte Usha Institute of Nursing \\ Sciences, Nitte (Deemed to be University), Derlakatte, Mangalore, \\ Karnataka, India \\ 2 Department of Community Health Nursing, Nitte Usha Institute of \\ Nursing Sciences, Nitte (Deemed to be University), Derlakatte, \\ Mangalore, Karnataka, India \\ J Health Allied Sci ${ }^{\mathrm{NU}}$ 2022;12:247-252.
}

\begin{abstract}
Address for correspondence Jacintha Veigas, PhD, Department of Community Health Nursing, Nitte Usha Institute of Nursing Sciences, Nitte (Deemed to be University), Paneer, Derlakatte, Mangalore 575018, Karnataka, India (e-mail: jacintha@nitte.edu.in).
\end{abstract}

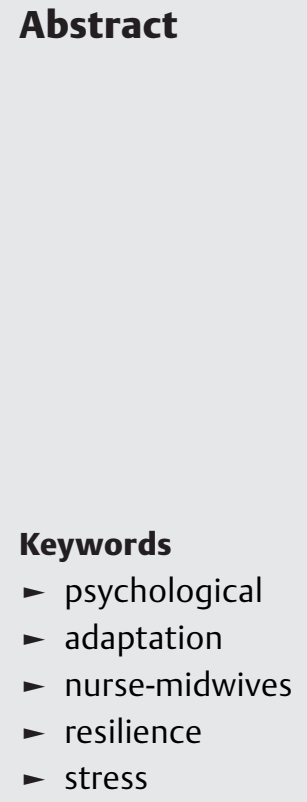

Objective A minimum amount of stress is essential for a successful life. When it goes beyond the limit, it affects overall well-being. There is a need to modify the environment, feelings, and physical factors of an individual to promote resilience. This study aimed to assess and find the relationship between perceived stress and resilience among nurses working in a selected hospital.

Materials and Methods The investigators used the descriptive correlation design and, through the nonprobability sampling method, selected 65 nurses. Data was collected using the demographic variables, perceived stress scale, and the ConnorDavidson resilience scale.

Results and Discussion The investigators found a moderate level of stress (61.5\%) with intermediate resilience $(73.8 \%$ ) among the nurses and noted a weak correlation between perceived stress and resilience (calculated value is 0.226 and the $p$-value is 0.071 ). There was an association found between the frequency of night duty, education level, and perceived stress.

Conclusion Our study showed that most of the nurses had a moderate level of stress with intermediate resilience. The unmarried nurses were more resilient, with a moderate level of stress than the married.

\section{Introduction}

Stress is an emerging issue in the present life of nurses. There are many factors that lead to stress among the nurses in workplace. The effect of perceived stress on nurses' health depends on their coping abilities and resilience. However, occupational stress is a universal phenomenon among professionals; nevertheless, the people fighting against it will succeed in their professional lives. Research focusing on nurses has commonly found that this population reports high levels of stress in their workplace.

Nursing is a profession with the highest level of stress, and they face stress due to various reasons. The sources of stress reported by nurses are as follows: workload, poor interpersonal relationships between patients and colleagues, and health factors. A study on health care workers revealed $68.2 \%$ workplace stress. ${ }^{1}$ published online

November 15, 2021
DOI https://doi.org/ 10.1055/s-0041-1736455. ISSN 2582-4287.

\footnotetext{
(C) 2021. Nitte (Deemed to be University). All rights reserved. This is an open access article published by Thieme under the terms of the Creative Commons Attribution-NonDerivative-NonCommercial-License, permitting copying and reproduction so long as the original work is given appropriate credit. Contents may not be used for commercial purposes, or adapted, remixed, transformed or built upon. (https://creativecommons.org/ licenses/by-nc-nd/4.0/)

Thieme Medical and Scientific Publishers Pvt. Ltd., A-12, 2nd Floor, Sector 2, Noida-201301 UP, India
} 
A nurse touches a life, or a life will influence her. Nursing is not only a career but also a form of social service that provides satisfaction to each one. The way that nurses look at the nursing profession will reflect the outcome. Like a coin, nursing profession also has two sides: negative (stress) and positive (satisfaction).

Nurses dedicate their professional lives to help and assist the dependent people. It causes disturbances in their personal as well as professional lives. It might be caused by severe workload, time constraints, lack of social support, coworker conflict, involvement with patients afflicted with infectious illnesses, sleep deprivation, or dealing with critically sick patients.

Some nurses are strong enough to handle these stressful situations while some are not. Healthy nurses are the ones who adopt a variety of coping strategies to overcome those stressful life events and maintain a stable life. Others will have burnout, which can affect them mentally and physically. Specific hospital units may occasionally cause persistent tension.

Resilience is the coping ability with the present strenuous situation and get back to the original state. Lower resilience may affect work pattern, which results in more conflicts, less productivity, frequent absenteeism, and psychological illeffects like depression. Nurses' resilience are bolstered by a variety of supporting initiatives such as stress busters.

A study by Mealer et al found that only $22 \%$ of intensive care unit (ICU) nurses are highly resilient. The presence of resilience in nurses was associated with a lower prevalence of posttraumatic stress, anxiety, depression symptoms, and burnout syndromes. Individuals with high-resilience capacity include internal locus of influence, empathy, positive selfimage, hopefulness, ability to consolidate everyday obligations, among other personal attributes. ${ }^{2}$

Ribeiro et al reported that $55.4 \%$ of the nurses had a propensity to develop burnout syndrome. The majority of the nurses were married, childless, and over 35 years old. They worked day shifts for an average of 36 hours a week, had 2 to 6 years of post-graduate experience, and did not have any additional responsibilities. The burnout can not only harm patient care but also affects concentration, motivation, and decision-making in nurses. ${ }^{3}$

A study on nurses' stress reported that the overall mean stress was more in the psychiatric unit than in other areas such as ICU/critical care unit (CCU) and emergency, medical and surgical wards. ${ }^{4}$ Most probably, the aggressive conduct, mandatory injections, physical constraints, fear of physical assault, uncertainty, and a lack of control over one's connection with patients are all factors that can add to stress among nurses.

Guo et al revealed severe burnout among nurses with a moderate level of resilience. The total score and the following characteristics of resilience revealed significantly negative relationships with three burnout markers. Linear regression analysis revealed resilience, particularly strength, as well as demographic (exercise, alcohol consumption, and marital status) and occupational (monthly income, patient-to-nurse ratio, shift work, and professional) factors. ${ }^{5}$ Cohen reported that resilience reviews are minimal and very uncertain. ${ }^{6}$

Resilience is a factor that should be strong in human beings. A health care industry demands several skills acquired/required by nurses. They need to adapt to numerous extensive roles. If they fail to acclimatize, they may not have a prospective career in their profession. Many recognize the importance of resilience, and strengthening programs are conducted to health professionals in various settings. To build resilience, the work environment must be encouraged, which will increase nurse retention and lower turnover.

In this study, perceived stress refers to the feelings or the thoughts that nurses experience at a given point of time during the working hours, which exerts pressure on them. In this study, resilience is the ability of the individual nurse to cope with or recover from stressful and difficult situations.

Assessing the stress reduction strategies, perceived controllability, intensity, and duration of stressors will be beneficial. The present study assesses the relation between stress and resilience of nurses.

\section{Materials and Methods}

A quantitative research approach with the descriptive correlation design was adapted for the study. The study was conducted in a full-fledged 1000-bedded teaching and superspecialty hospital with 12 broad specialties and 15 superspecialties situated at Deralakatte, approximately $16 \mathrm{~km}$ from the heart of the city of Mangaluru. The daily bed occupancy ranges from 500 to 700 . There are around 325 registered nurses employed in this hospital. The nurse-topatient ratio is maintained based on the patients' ability. In general wards, one nurse is responsible for 5 to 10 patients, while in special areas, one nurse is responsible for one to three patients.

Team nursing is used for patient care assignment, based on a philosophy in which groups of professionals and nonprofessionals work together to develop, plan, implement, and evaluate full client-centered care. A senior registered nurse (RN) leads the team of other registered nurses, and the team members offer direct patient care to a group of patients in a coordinated effort under the guidance of the RN team leader.

Nurses working in casualty, medical, and surgical wards with a minimum of one year of experience were recruited to the study, and a total of 65 nurses were chosen using convenience sampling. This method was chosen because more than 100 nurses had less than 1 year of experience.

$$
n=\frac{Z^{2} 1-\alpha / 2 P(1-P)}{d^{2}}
$$

Using the above estimation of a single proportion formula, the investigator calculated the sample size ( $\alpha$ indicates the level of significance, $d$ is precision-0.1, and the anticipated proportion is $\mathrm{P}-30$ ). As per the above formula, the estimated sample size was 65; hence, data from 65 nurses were 
collected using the demographic proforma, perceived stress scale (PSS), and resilience scale.

Staff nurses with more than 1 year experience and senior staff nurses with more than 5 years were included in this study. In the hospital, there were two shifts. Regular day shift was from 8.00 Am to 6.00 PM except the postoperative and casualty units which function for 6 hours per shift. Nurses are on night duty from 6 pM to 6 AM.

Age, place of origin, degree of education, clinical experience area, number of life-threatening patients treated for in the previous month, years of clinical experience, marital status, number of children, frequency of night duty, and number of working hours/weeks are all demographic characteristics. To learn about the stress caused by a change of location, the location of origin was included. Assuming that the change of place might have some influence in causing stress in nurses, item on place of origin was added in the demographic proforma.

A PSS is a standardized tool developed by Cohen. It is a commonly used psychological instrument to assess the perception of stress. The PSS-10's psychometric qualities were first tested on a large national sample of 2,387 people in the United States. Scores on the PSS-10 showed adequate internal consistency reliability (0.78), according to Cohen. This scale has different direct queries that will help to find the current level of experienced stress. All the queries are self-explanatory. The scale has 10 questions, out of which four were positively stated and six were negatively stated. All the items were focusing on the feelings and thoughts experienced during the last month. Each question asked the participants how they felt a certain way. Instructions were given to the participants to read the question carefully and place a tick mark in any column which they found suitable from the alternatives, such as never (0), almost never (1), sometimes (2), fairly often (3), and very often (4). The investigator scored negative items in reverse order. The maximum score was 40 , and the minimum score was 0 . Scores were interpreted as low-level stress if they were between 0 to 13 , moderate level stress if they were between 14 to 26 , and high-level stress if they were between 27 to $40 .^{6}$

Connor-Davidson resilience scale is also a standardized tool that measures the ability of a person to bounce back in the face of hardship. The investigator obtained permission from the author to use the tool. The scale had 25 items with simple and understandable statements, and the participants were informed to read and mark them. It had six options such as not true at all, rarely true, sometimes true, often true, true nearly, and true all the time. The six-point Likert scale ranging from 0 to 5 , and the maximum score was 125 , and the minimum score was zero. The person with the highest score had maximum resilience. The resilience level was calculated using quartile ranges of the 25th (least resilience), 50th (intermediate resilience), and 75th (high resilience) quartiles. Q1, Q2, and Q3 were derived based on the median score. The median of the lower half of the data is the first quartile, represented by Q1. The second quartile (Q2), also known as the 50th percentile or median, is defined as the point at which half of the data falls below Q2 and the other half falls above Q2. The third quartile (Q3), also known as the 75 th percentile, is defined as the point when $75 \%$ of the data falls below Q3 and $25 \%$ of the data falls above Q3. Cronbach's $\alpha$ for the complete Connor-Davidson resilience scale was 0.89 for group $1(n=577)$ by using Cronbach's $\alpha{ }^{7}$

The nurses spent 30 to 45 minutes to complete the tools listed above.

\section{Protection of Human Subjects' Rights}

The study was submitted and presented to the institutional ethics committee for ethical clearance and obtained permission. The hospital authorities permitted the investigators to conduct the study among nurses. The investigator explained the study purpose, assured confidentiality, and obtained written informed consent. Each subject participated in this study willingly. The investigator collected data by using the self-reported questionnaire, and it took around 30 to 40 minutes to complete the tools. The investigator made sure that there was no contamination of data.

Data were analyzed using descriptive and inferential statistics. Calculated perceived stress and resilience using frequency, percentage, mean, standard deviation (SD), median, and interquartile range (IQR). We determined the relationship between perceived stress and resilience using the Karl Pearson correlation. We used Chi-square to see whether there is an association between perceived stress and certain demographic variables. The $p$-value of less than 0.05 was considered significant.

\section{Results}

The majority $(42 ; 64.6 \%)$ of the nurses were in the age group of 21 to 25 years, and 36 (55.4\%) nurses completed the general nursing and midwifery (GNM) program. Sixteen (24.6\%) nurses were from the surgical wards, and $44.6 \%$ had experience in caring for three to four patients with life-threatening conditions like diabetes, seizure disorder, severe asthma, cardiac conditions in last month (January 2019). A total of 39 (60\%) nurses had 3 to 6 years of experience, 41 (63.1\%), nurses had a frequency of night duty once in a month, and 46 (71\%) nurses were unmarried (-Table 1). The mean distribution of number of hours worked by nurses per week was $57.78 \pm 4.65$, and the mean distribution of number of years of clinical experience was $4.2 \pm 1.81$.

The mean and SD values of the variables also proved the data's normality. Furthermore, the normal distribution of data of both variables (stress and resilience) were analyzed using Shapiro-Wilk test and found " $p$ " values were found to be $>0.05$. It indicates that variables are normally distributed in the population.

A total of 22 (33.8\%) nurses experienced a low level of stress, 40 (61.5\%) had moderate stress, and 3 (4.6\%) had high stress.

The median score of the analyzed resilience scores was 82 , with the lowest resilience scores ranging from 0 to 64.5 in the 25th quartile, intermediate resilience scores ranging from 
Table 1 Demographic variables of nurses, $n=65$

\begin{tabular}{|c|c|c|c|}
\hline SI. no. & Demographic variables & $\begin{array}{l}\text { Frequency } \\
\text { (f) }\end{array}$ & $\begin{array}{l}\text { Percentage } \\
\text { (\%) }\end{array}$ \\
\hline \multirow[t]{5}{*}{1} & \multicolumn{3}{|l|}{ Age } \\
\hline & a) $21-25$ & 42 & 64.6 \\
\hline & b) $26-30$ & 14 & 21.5 \\
\hline & c) $31-35$ & 6 & 9.2 \\
\hline & d) $>36$ & 3 & 4.6 \\
\hline \multirow[t]{4}{*}{2} & \multicolumn{3}{|l|}{ State } \\
\hline & a) Karnataka & 45 & 69.2 \\
\hline & b) Kerala & 18 & 27.7 \\
\hline & c) Other states & 2 & 3.1 \\
\hline \multirow[t]{3}{*}{3} & \multicolumn{3}{|l|}{ Level of education } \\
\hline & a) GNM & 36 & 55.4 \\
\hline & b) $\mathrm{BSC}$ & 29 & 44.6 \\
\hline \multirow[t]{9}{*}{4} & \multicolumn{3}{|l|}{ Area of clinical experience } \\
\hline & a) Medical ward & 6 & 9.2 \\
\hline & b) Surgical ward & 16 & 24.6 \\
\hline & c) Neurology & 4 & 6.2 \\
\hline & d) Urology & 4 & 6.2 \\
\hline & e) Casualty & 6 & 9.2 \\
\hline & f) Postoperative ward & 10 & 15.4 \\
\hline & g) Ortho ward & 13 & 20 \\
\hline & h) ENT & 6 & 9.2 \\
\hline \multirow[t]{5}{*}{5} & \multicolumn{3}{|c|}{ Number of life-threatening patients cared in the last month } \\
\hline & a) $<1$ patient & 16 & 24.6 \\
\hline & b) 1-3 patients & 16 & 24.6 \\
\hline & c) 3-6 patients & 29 & 44.6 \\
\hline & d) $>6$ patients & 4 & 6.2 \\
\hline \multirow[t]{4}{*}{6} & \multicolumn{3}{|l|}{ Years of clinical experience } \\
\hline & a) $1-3$ years & 17 & 26.2 \\
\hline & b) 3-6 years & 39 & 60.0 \\
\hline & c) $>6$ years & 9 & 13.8 \\
\hline \multirow[t]{3}{*}{7} & \multicolumn{3}{|l|}{ Marital Status } \\
\hline & a) Single & 46 & 70.8 \\
\hline & b) Married & 19 & 29.2 \\
\hline \multirow[t]{5}{*}{8} & \multicolumn{3}{|c|}{ Number of children $(n=19)$} \\
\hline & a) No children & 6 & 32.0 \\
\hline & b) 1 & 7 & 37.0 \\
\hline & c) 2 & 4 & 21.0 \\
\hline & d) $>3$ & 2 & 10.0 \\
\hline \multirow[t]{4}{*}{9} & \multicolumn{3}{|l|}{ Frequency of night duty } \\
\hline & a) Once in month & 41 & 63.1 \\
\hline & b) Once in 3 weeks & 5 & 7.7 \\
\hline & c) Once in 2 weeks & 19 & 29.2 \\
\hline \multirow[t]{3}{*}{10} & \multicolumn{3}{|c|}{ Number of working hours/week } \\
\hline & a) 48 hours & 12 & 18.5 \\
\hline & b) 60 hours & 53 & 81.5 \\
\hline
\end{tabular}

Abbreviations: BSc, Bachelor of Science; GNM, general nursing and midwifery.
Table 2 Frequency distribution of the level of perceived stress and resilience of nurses, $n=65$

\begin{tabular}{|c|c|c|}
\hline Variables & $\begin{array}{l}\text { Frequency } \\
\text { (f) }\end{array}$ & $\begin{array}{l}\text { Percentage } \\
\text { (\%) }\end{array}$ \\
\hline \multicolumn{3}{|l|}{ Perceived stress } \\
\hline Low-level stress & 22 & 33.8 \\
\hline Moderate-level stress & 40 & 61.5 \\
\hline High-level stress & 3 & 4.6 \\
\hline \multicolumn{3}{|l|}{ Resilience } \\
\hline $\begin{array}{l}\text { The least resilience } \\
\text { (25th quartile) }\end{array}$ & 19 & 29 \\
\hline $\begin{array}{l}\text { Intermediate resilience } \\
\text { (50th quartile) }\end{array}$ & 31 & 48 \\
\hline $\begin{array}{l}\text { High resilience } \\
\text { (75th quartile) }\end{array}$ & 15 & 23 \\
\hline
\end{tabular}

64.5 to 96.5 in the 50th quartile, and high-resilience scores ranging from 96.5 to 125 in the 75th quartile. Based on the median score, the calculated Q1 value was 64.5 , Q2 was 82 , and Q3 was 96.5 . Nineteen (29\%) had the least resilience, 31 (48\%) had intermediate resilience, and 15 (23\%) had high resilience (-Table $\mathbf{2}$ ).

The mean stress score was 15.89 with a $\mathrm{SD}$ of \pm 7.065 , and for resilience, the mean score had a SD of $80.1( \pm 22.06)$. The Pearson correlation coefficient value for the total stress and the resilience was 0.226 , which shows a weak correlation between perceived stress and resilience ( - Table 3 ).

\section{Discussion}

In the present study, the results showed that most of the participants belonged to the age group of 21 to 25 years (64.6\%), 69.2\% belonged to Karnataka state, and 55.4\% were with the qualification of GNM. Most of the participants (60\%) had 3 to 6 years of clinical experience. The majority of nurses were unmarried $(71 \%)$ and had a night duty frequency of once in a month with 60 hours of workload per week.

A similar comparative study conducted by Jordan et al on perceived stress in nurses showed that, among the 360 nurses, most of the nurses were in the age group between 22 and 44 years, and almost $68 \%$ reported that they had one to three children. Only 32\% reported having no children. Ninety-one percent had a bachelor's degree, and others completed postgraduation. ${ }^{8}$

\section{The Level of Perceived Stress and Resilience among Nurses}

In the present study, most of them were having moderate stress with intermediate resilience. The results show that there is a need for educational sessions to improve resilience and reduce stress.

A similar result was found in a study conducted by Koen et al on the effect of stress level and the coping mechanism in which $92 \%$ of the nurses from selected 120 samples reported 
Table 3 Correlation between perceived stress and resilience of nurses $n=65$

\begin{tabular}{|l|l|l|l|l|l|l|}
\hline Variable & Mean & SD & Minimum & Maximum & Pearson correlation & $p$-Value \\
\cline { 1 - 5 } Perceived stress & 15.89 & 7.065 & 2 & 34 & 0.226 & 0.071 \\
\cline { 1 - 5 } Resilience & 80.11 & 22.065 & 1 & 119 & \\
\hline
\end{tabular}

Abbreviation: SD, standard deviation.

Table 4 Association of perceived stress of nurses with selected demographic variables

\begin{tabular}{|c|c|c|c|c|c|c|}
\hline $\begin{array}{l}\text { Demographic } \\
\text { variables }\end{array}$ & $\begin{array}{l}\text { Median less } \\
\text { than } 17\end{array}$ & $\begin{array}{l}\text { Median } \\
\text { more than or } \\
\text { equal to } 17\end{array}$ & Total & Chi-square & df & $p$-Value \\
\hline \multicolumn{7}{|l|}{ Age in years } \\
\hline a) 21-25 & 23 & 19 & 42 & \multirow[t]{4}{*}{1.842} & \multirow[t]{4}{*}{3} & \multirow[t]{4}{*}{0.606} \\
\hline b) $26-30$ & 5 & 9 & 14 & & & \\
\hline c) $31-35$ & 3 & 3 & 6 & & & \\
\hline d) $>36$ & 1 & 2 & 3 & & & \\
\hline \multicolumn{7}{|l|}{ Level of education } \\
\hline a) GNM & 23 & 13 & 36 & \multirow[t]{2}{*}{6.936} & \multirow[t]{2}{*}{1} & \multirow{2}{*}{$\begin{array}{l}0.008 \\
{ }^{*} S\end{array}$} \\
\hline b) $\mathrm{BSc}$ & 9 & 20 & 29 & & & \\
\hline \multicolumn{7}{|c|}{ Number of life-threatening patients cared in the last month } \\
\hline a) $<1$ patient & 8 & 8 & 16 & \multirow[t]{4}{*}{2.296} & \multirow[t]{4}{*}{3} & \multirow[t]{4}{*}{0.513} \\
\hline b) 1-3 patients & 10 & 6 & 16 & & & \\
\hline c) 3-6 patients & 13 & 16 & 29 & & & \\
\hline d) $>6$ patients & 1 & 3 & 4 & & & \\
\hline \multicolumn{7}{|l|}{ Frequency of night duty } \\
\hline a) Once in month & 25 & 16 & 41 & \multirow[t]{3}{*}{8.531} & \multirow[t]{3}{*}{2} & \multirow{3}{*}{$\begin{array}{l}0.014 \\
{ }^{*} S\end{array}$} \\
\hline b) Once in 3 weeks & 3 & 2 & 5 & & & \\
\hline c) Once in 2 weeks & 4 & 15 & 1 & & & \\
\hline \multicolumn{7}{|c|}{ Number of working hours per week } \\
\hline a) 48 hours & 7 & 5 & 12 & \multirow[t]{2}{*}{0.488} & \multirow[t]{2}{*}{1} & \multirow[t]{2}{*}{0.485} \\
\hline b) 60 hours & 25 & 28 & 53 & & & \\
\hline
\end{tabular}

Abbreviations: BSc, Bachelor of Science; GNM, general nursing and midwifery.

Note: $p<0.05$.

moderate to very high stress levels and only $8 \%$ reported having low or very low stress. ${ }^{9}$

Delgado et al in a cross-sectional study of 312 nurses found similar findings when it came to the prevalence of resilience. The result shows public health care nurses had lesser levels of resilience than nurses in the private sector. Ten percent reported low resilience, $47 \%$ reported moderate resilience and $43 \%$ were highly resilient. Many nurses were emotionally burdened, which resulted in stress, fatigue, frustration, irritation, and lack of job satisfaction. Resilience interventions build nurses' resources significantly and have effects on nursing work emotional dissonance. It is also suggested to have further studies for strong evidence. ${ }^{10}$ Another study by Kunzler et al reports resilience training among health care workers may reduce symptoms of depression and stress immediately or at the end of treatment. $^{11}$

\section{Correlation between Perceived Stress and Resilience among Nurses}

In this study, the findings showed a weak correlation between perceived stress and resilience of nurses. The correlation between the total perceived stress and total resilience was identified by applying the Pearson correlation and the value was 0.226 . As the $p$-value was 0.071 , it was more than 0.05 . Hence, the null hypothesis was accepted.

In 2015, contradictory findings were published by Rushton et al on burnout and resilience among nurses working in high-intensity settings. It was identified that the relationship between burnout and resilience was strong. A higher level of 
resilience was associated with increased hope and reduced stress levels. $^{12}$

\section{Association between Perceived Stress and Resilience among the Nurses with the Selected Demographic Variables}

In this study, a significant association was observed between perceived stress and the level of education of nurses ( $\mathrm{X}^{2}=6.936, \mathrm{df}=1, p=0.008$ ). Also, a significant association was found between the frequency of night duty in a month with the stress level $\left(\mathrm{X}^{2}=8.531, \mathrm{df}=1, p=0.014\right)$ ( - Table 4).

In a study of 275 nurses on job stressors, coping, and resilience, Lanz and BrukLee identified that certain demographic variables such as age, sex, and years of service had little bearing on resilience. They also mentioned the fear of making a mistake in treating a patient and their coping abilities were negatively related. ${ }^{13}$

In a report on the impact of stress on critical care nurses, Benadé et al noted that stress was negatively correlated with increased age and marital status. The number of beds in ICU, type of intensive care, educational level of nurses, shift time, working on holidays, and demographic factors like the number of children and body mass index (BMI) were also not associated with the level of stress. ${ }^{14}$

The highly resilient nurses had a significant association with less posttraumatic stress disorder, anxiety or depression and burnout syndrome $(<0.001)$. Only $20 \%$ of ICU nurses were highly resilient. ${ }^{2}$

In this study, only a few demographic variables had a significant association with perceived stress. An important finding also was observed, in that the majority of the nurses were unmarried, so the absence of a significant family or pressure from family might have given them adequate space and the ability to be more resilient with a moderate amount of stress.

\section{Conclusion}

The majority of the nurses in this research reported intermediate level of resilience and moderate stress. Nursing is a physically demanding career, and stress is a common occurrence in everyday life. Continuous assistance from higher authorities is required along with different stress-relieving and resilience-building approaches.

\section{Institutional Review Board Approval}

The study was submitted and presented to the institutional ethics committee for ethical clearance and obtained permission.
Conflict of Interest

None declared.

Acknowledgment

The authors of this article would like to express their gratitude to the Nitte (Deemed to be University) for their assistance and support.

\section{References}

1 Birhanu M, Gebrekidan B, Tesefa G, Tareke M. Workload determines workplace stress among health professionals working in Felege-Hiwot Referral Hospital, Bahir Dar, Northwest Ethiopia. J Environ Public Health 2018;2018:6286010

2 Mealer M, Jones J, Newman J, McFann KK, Rothbaum B, Moss $M$. The presence of resilience is associated with a healthier psychological profile in intensive care unit (ICU) nurses: results of a national survey. Int J Nurs Stud 2012;49(03): 292-299

3 Ribeiro VF, Filho CF, Valenti VE, et al. Prevalence of burnout syndrome in clinical nurses at a hospital of excellence. Int Arch Med 2014;7(01):22

4 Masa'Deh R, Alhalaiqa F, AbuRuz ME, Al-Dweik G, Al-Akash HY. Perceived Stress in Nurses: A Comparative Study. Glob J Health Sci 2016;9(06):195

5 Guo Y-F, Luo Y-H, Lam L, Cross W, Plummer V, Zhang J-P. Burnout and its association with resilience in nurses: A cross-sectional study. J Clin Nurs 2018;27(1-2):441-449

6 Cohen S. Perceived stress in a probability sample of the United States. In: S. Spacapan, S. Oskamp, eds. The Social Psychology of Health. Sage Publications, Inc.1988:31-67

7 Connor KM, Davidson JRT. Development of a new resilience scale: the Connor-Davidson Resilience Scale (CD-RISC). Depress Anxiety 2003;18(02):76-82

8 Jordan TR, Khubchandani J, Wiblishauser M. The impact of perceived stress and coping adequacy on the health of nurses: A pilot investigation. Nurs Res Pract 2016;2016:5843256

9 Koen MP, Van Eeden C, Wissing MP. The prevalence of resilience in a group of professional nurses. Health SA Gesondheid (Online) 2011;16:1-11

10 Delgado C, Upton D, Ranse K, Furness T, Foster K. Nurses' resilience and the emotional labour of nursing work: an integrative review of empirical literature. Int J Nurs Stud 2017;70:71-88

11 Kunzler AM, Helmreich I, Chmitorz A, et al. Psychological interventions to foster resilience in healthcare professionals. Cochrane Database Syst Rev 2020;7:CD012527

12 Rushton CH, Batcheller J, Schroeder K, Donohue P. Burnout and resilience among nurses practicing in high-intensity settings. Am J Crit Care 2015;24(05):412-420

13 Lanz JJ, Bruk-Lee V. Resilience as a moderator of the indirect effects of conflict and workload on job outcomes among nurses. J Adv Nurs 2017;73(12):2973-2986

14 Benadé P, du Plessis E, Koen MP. Exploring resilience in nurses caring for older persons. Health SA Gesondheid 2017; 22:138-149 